\title{
Histopathological study of endometrial stromal sarcomas
}

\author{
Salma Bhat, Ambreen Beigh*, Summyia Farooq
}

Department of Pathology, GMC, Srinagar, Jammu and Kashmir, India

Received: 30 July 2018

Revised: 11 September 2018

Accepted: 21 October 2018

\section{*Correspondence:}

Dr. Ambreen Beigh,

E-mail: ambreenbeigh26@gmail.com

Copyright: (c) the author(s), publisher and licensee Medip Academy. This is an open-access article distributed under the terms of the Creative Commons Attribution Non-Commercial License, which permits unrestricted non-commercial use, distribution, and reproduction in any medium, provided the original work is properly cited.

\begin{abstract}
Background: Endometrial stromal sarcomas (ESSs) are rare malignant uterine tumours comparatively affecting younger women and the mean age is 42 to 58 years. The World Health Organization (WHO) classification categorises endometrial stromal neoplasms and related tumors as: endometrial stromal nodule (ESN), low-grade endometrial stromal sarcoma (LG-ESS), high-grade endometrial stromal sarcoma (HG-ESS), and undifferentiated uterine sarcoma (UUS).

Methods: Present study is a retrospective one and includes 6 patients with histologically proven endometrial stromal sarcoma for a period of 3 years. Authors examined every slide available from each case and new HE-stained slides generated from formaline-fixed, paraffin-embedded tissue were reviewed to confirm the diagnoses. Demographic information, pathologic, and treatment information were collected from the clinic and hospital charts. All had primary surgical management in the form of total abdominal hysterectomy and salpingo-oophorectomy.

Results: The mean patient age was 41 years. All of the patients had presented with abnormal uterine bleeding. Diffuse growth of small cells closely resembling those of the normal proliferative endometrial stroma was the characteristic feature of these tumors. All of these patients had a low grade ESS on histopathology. They had regular follow-up visits until the end of study.

Conclusions: Endometrial stromal sarcomas are rare malignant tumors of the uterus and a proper preoperative diagnosis is difficult. Their differential diagnosis from typical submucosal uterine myomas or benign endometrial polyps can be difficult. The histological examination of the specimen is necessary to exclude malignancy and establish the final diagnosis.
\end{abstract}

Keywords: Endometrial, Histology, Sarcoma, Stromal

\section{INTRODUCTION}

Endometrial stromal sarcomas (ESSs) are rare malignant uterine tumors that make up approximately $10 \%$ of all uterine sarcomas but only around $0.2 \%$ of all uterine malignancies. ${ }^{1}$ ESS comparatively affects younger women and the mean age is 42 to 58 years. $^{2}$ The World Health Organization (WHO) classification categorises endometrial stromal neoplasms and related tumors as: endometrial stromal nodule (ESN), low-grade endometrial stromal sarcoma (LG-ESS), high-grade endometrial stromal sarcoma (HG-ESS), and undifferentiated uterine sarcoma (UUS). ${ }^{3}$ The usual clinical presentation of ESS is abnormal uterine bleeding that occurs in about $90 \%$ of women and $70 \%$ cases show uterine enlargement. They can present with pelvic pain and dysmenorrhoea. An asymptomatic ESS occurs in $25 \%$ individuals. ${ }^{4}$ About 30 to $50 \%$ of the ESS has extra uterine spread at the time of the diagnosis. ${ }^{2}$ While LGESS is a clinically indolent neoplasm harbouring minimal 
cytological atypia, infrequent mitotic figures, and numerous thin-walled small arteriolar type vessels, the undifferentiated endometrial sarcoma is a highly agressive tumor that lacks a plexiform vasculature, features severe cytological atypia, and has frequent often atypical mitotic figures., ${ }^{5,6}$ In the uterine corpus, ESS characteristically shows prominent 'finger-like' myometrial infiltration with lymphovascular permeation. ESS in its 'classic' form is composed of a proliferation of small, round monomorphic cells with scanty cytoplasm and round to oval nuclei with smooth nuclear contours, resembling non-neoplastic proliferative-phase endometrial stroma. The mitotic index, size, stage, histological grade, positive surgical margins, menopause and age have been reported as potential prognostic parameters, but their use in ESS remains dubious. ${ }^{7,8}$ In this study, the clinical and pathological features of endometrial stromal sarcomas are described to better define their characteristics and outcome.

\section{METHODS}

\section{Inclusion criteria}

- This observational retrospective study included patients with histologically proven endometrial stromal sarcoma for a period of 3 years (2015-2017).

Gross examination notes were found in the surgical pathology reports and clinical information was obtained from the Department of Obstetrics and Gynecology. Authors examined every slide available from each case and new HE-stained slides generated from formalinefixed, paraffin-embedded tissue were reviewed to confirm the diagnoses. Endometrial stromal differentiation was recognized as small cells with scant cytoplasm and round to ovoid nuclei. The accompanying vasculature included spiral arteriole- like vessels, and staghorn vessels. Diagnosis of ESS were based on infiltrative margin and/or vascular invasion.

\section{Exclusion criteria}

- Cases of histopathologically proven endometrial stromal nodule and undifferentiated uterine sarcomas were excluded from the study.

Demographic information, pathologic, and treatment information were collected from the clinic and hospital charts. All had primary surgical management in the form of total abdominal hysterectomy and salpingooophorectomy. They had regular follow-up visits until the end of study.

\section{RESULTS}

\section{Clinical features}

The mean patient age was 41 years. All of the patients had presented with abnormal uterine bleeding. Clinical presentation of two cases were submucosal and intramural myoma. One of the cases was found incidentally after TAH+BSO performed for other reasons.

\section{Gross features}

The tumor ranged 4 to $6 \mathrm{~cm}$ (mean $5 \mathrm{~cm}$ ) in maximal dimension and each grossly presented as a wellcircumscribed mass and resembled leiomyoma macroscopically. Four tumors were polypoid, projected into the endometrial cavity, and described as "submucosal" masses. Two cases were described as "intramural"mass. The cut surfaces were fleshy and uniformly yellow-white. None of them had hemorrage, necrosis, cyst and ulceration (Figure 1).

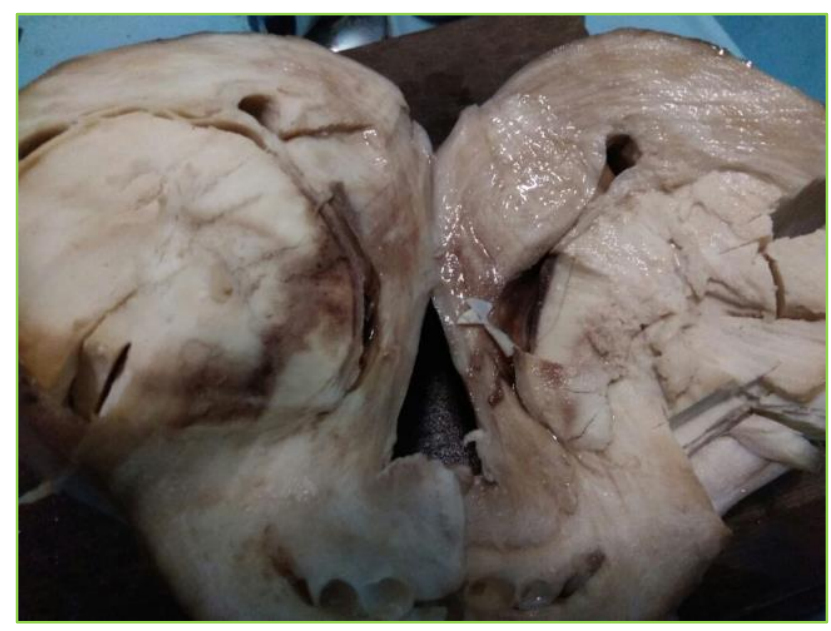

Figure 1: Endometrial stromal sarcoma presenting as a large mass occupying most of the endometrial cavity.

\section{Microscopic features}

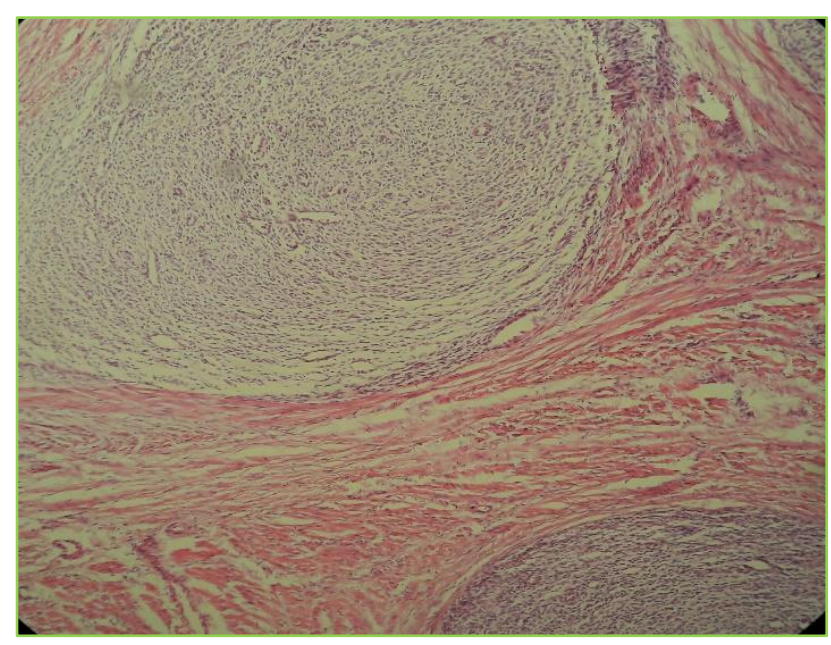

Figure 2: Nodules of neoplastic endometrial stromal cells in the full thickness of myometrium; the tumor cells demonstrate a tendency to make whorls around the arterioles. 
Diffuse growth of small cells closely resembling those of the normal proliferative endometrial stroma was the characteristic feature of these tumors. The tumor cells were typicially oval to spindle shaped and small or medium with scant to occasionally more appreciable cytoplasm. The nuclei were uniformly oval to fusiform with inconspicuous nucleoli. No bizarre nuclei or mitotic figures were detected. Typical arterioles were numerous in two neoplasms. The tumor cells occasionally exhibited a tendency to make whorls around the arteioles (Figure 2). All of these patients had a low grade ESS on histopathology. Two LGESS cases were similar to ESN morphologically, despite showing myometrial and vascular invasion (Figure 3) and mitotic activity in one case.

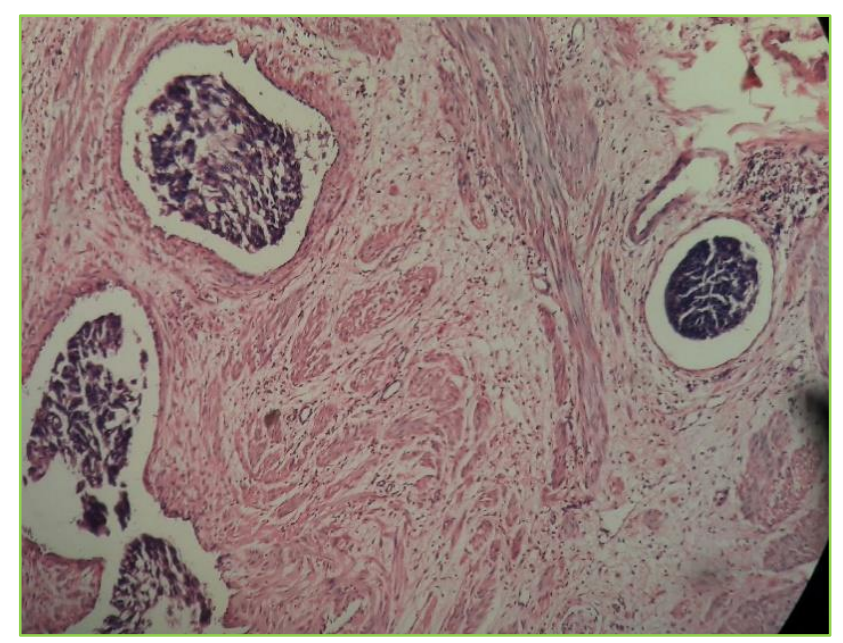

Figure 3: Lymphovascular invasion as seen in ESS.

\section{DISCUSSION}

Endometrial stromal sarcoma (ESS) is the second most common type of uterine sarcoma. In the latest World Health Organization classification, ESSs are classified into low-grade and high-grade subtypes. ${ }^{3}$ Although infrequent, uterine sarcomas are among the most lethal of all uterine malignancies. The 5-year survival rate reportedly ranges from $30 \%$ to $68 \% .^{7}$ ESS can be mistaken for a leiomyoma and the diagnosis is often made postoperatively after histological examination. ${ }^{8}$ Authors report six cases of ESS in present study. Three patients in present study presented with irregular menstrual bleeding with hysterectomy performed for a leiomyoma. Two of our patients presented with postmenopausal bleeding. One of the cases was found incidentally after TAH+BSO performed for other reasons. All of these patients had a low grade ESS on histopathology. The mean age at presentation in present study was 41 years. Women with LGESS are younger than women with other uterine sarcomas, with a median age between 45 and 57 years. ${ }^{1}$ Majority of low grade ESS occur in the perimenopausal period, occasionally arising in young women and adolescents. Patients usually present with vaginal bleeding or pelvic pain. ${ }^{9}$
Low grade endometrial stromal sarcoma is an infrequent tumor of the uterus. Its gross appearance may be that of a submucous polyp, or an intra-myometrial mass. ${ }^{10}$ The classical gross appearance of an intra-myometrial mass is either a single nodule, multiple solid-cystic masses, or a poorly demarcated solid-cystic lesion. ${ }^{11}$

In the uterine corpus, ESS characteristically shows prominent 'finger-like' myometrial infiltration with lympho-vascular permeation (Figure 1). ESS in its 'classic' form is composed of a proliferation of small, round monomorphic cells with scanty cytoplasm and round to oval nuclei with smooth nuclear contours, resembling non-neoplastic proliferative-phase endometrial stroma (Figure 2 and 3). The mitotic index, size, stage, histological grade, positive surgical margins, menopause and age have been reported as potential prognostic parameters, but their use in ESS remains dubious. ${ }^{12,13}$ The results of a study of 831 women with ESSs showed that age, race, stage, and grade of disease are important independent prognostic factors for survival. The survival of more than $90 \%$ in patients with grades 1 and 2 disease compared with only $42 \%$ in those with grade 3 disease supports the concept that low-grade ESSs have a significantly different clinical behaviour from high-grade tumors. ${ }^{14}$ All our patients are doing well and are on follow-up.

\section{CONCLUSION}

Endometrial stromal sarcomas are rare malignant tumors of the uterus and a proper preoperative diagnosis is difficult. Their differential diagnosis from typical submucosal uterine myomas or benign endometrial polyps can be difficult. The histological examination of the specimen is necessary to exclude malignancy and establish the final diagnosis.

\section{Funding: No funding sources \\ Conflict of interest: None declared}

Ethical approval: The study was approved by the Institutional Ethics Committee

\section{REFERENCES}

1. Ashraf-Ganjoei T, Behtash N, Shariat M, Mosavi A. Low grade endometrial stromal sarcoma of uterine corpus, a clinico-pathological and survey study in 14 cases. World J Surg Oncol. 2006;4:50.

2. Tavassoli FA, Devilee P. WHO Classification of Pathology and genetics of tumours of the breast and female genital organs. In: Tavassoli FA, Devilee P, eds. Lyon, France: IARC Press; 2003:233-236.

3. Conklin CM, Longacre TA. Endometrial stromal tumors: the new WHO classification. Adv Anat Pathol. 2014;21:383.

4. Puliyath G, Nair MK. Endometrial stromal sarcoma: A review of the literature. Indian $\mathrm{J}$ Med Paediatr Oncol: Official J Indian Soc Med Paediatr Oncol. 2012;33(1):1-6. 
5. Nucci MR, O'Connell JT, Huettner PC, Cviko A, Quade BJ. H- Caldesmon expression effectively distinguishes endometrial stromal tumors from uterine smooth muscle tumors. Am J Surg Pathol. 2001;25(4):455-63.

6. Diagoni A, Oliva, Clement PB, Young RH. Endometrial stromal nodules and endometrial stromal tumors with limited infiltration. Am J Surg Pathol. 2002;26(5):567-81.

7. Blythe JG, Bari WA. Uterine sarcoma: Histology, classification and prognosis. Global Lib Women's Med. 2008.

8. Ashraf-Ganjoei T, Behtash N, Shariat M, Mosavi A. Low grade Endometrial Stromal Sarcoma of uterine corpus, a clinico-pathological and survey study in 14 cases. World J Surg Oncol. 2006;4:50.

9. Ali RH, Al-Safi R, Al-Waheeb S, John B, Al-Ali W, Al-Jassar W, et al. Molecular characterization of a population-based series of endometrial stromal sarcomas in Kuwait. Hum Pathol. 2014;45:2453-62.

10. Ansari M, Parulekar SV. Low grade endometrial stromal sarcoma: unusual gross appearance. JPGO 2015;2(4).
11. Pekindil G, Tuncyurek O, Orguc S, Inceboz U, Kandiloglu AR, Caglar H. A case of endometrial stromal sarcoma with curvilinear calcification. Gynecol Oncol. 2005;98:318-21.

12. Haberal A, Kayikcioglu F, Boran N, Caliskan E, Ozgul N, Kose MF. Endometrial stromal sarcoma of the uterus: analysis of 25 patients. Eur J Obstet Gynecol Reprod Biol. 2003;109:209-13.

13. Leath III CA, Huh WK, Hyde Jr J, Cohn DE, Resnick KE, Taylor NP, et al. A multi institutional review of outcomes of endometrial stromal sarcoma. Gynecol Oncol. 2007;105:630-4.

14. Chan JK, Kawar NM, Shin JY, Osann K, Chen LM, Powell CB, et al. Endometrial stromal sarcoma: a population-based analysis. Brit $\mathrm{J}$ Cancer. 2008;99(8):1210-5.

Cite this article as: Bhat $\mathrm{S}$, Beigh $\mathrm{A}$, Farooq $\mathrm{S}$. Histopathological study of endometrial stromal sarcomas. Int J Reprod Contracept Obstet Gynecol 2018;7:4891-4. 